\title{
THE REPRESENTATIONAL FALLACY AND THE ONTOLOGY OF TIME
}

\section{INTRODUCTION}

In Metaphysics and the Representational Fallacy, Heather Dyke, notices that while most work in contemporary Metaphysics takes itself to be an enquiry into the fundamental nature and structure of reality, a flawed methodology has been used in pursuit of this aim. Philosophers have been examining language in order to try to uncover ontological truths about reality. As a result, their arguments move from facts about language to facts about reality. The debate concerning the ontological status of tense ${ }^{1}$ in the philosophy of time brings this flawed methodology to light. In order to argue for their respective ontological positions, the A-theorist and the B-theorist ${ }^{2}$ place an unusual amount of emphasis on our temporal language. In this paper, I will call this methodology into question. I will argue that it is fallacious to argue from claims about language to conclusions about reality; it is committing a fallacy called the representational fallacy. ${ }^{3}$ I will use the argument from tense in the philosophy of

1 Tense in language is when a speaker talks about or refers to a moment in time, relative to the moment in time from which he or she is speaking. Most languages include phrases that suggest past, present and future with respect to the moment of time from which the utterer is speaking. i.e. If I say "It is raining now," this is a (present) tensed phrase because "is" and "now" indicate the moment of time that I am uttering it (which is the present, it is raining now). Thus, these phrases depend on context. This will be addressed further in sections 4 and 5 .

2 A-theory and B-theory are two different ways of thinking about time and how it works.

3 A term coined by Heather Dyke (2007). In Metaphysics and the Representational Fallacy, 1. London: Routledge. 
time to betray this fallacy, and to argue that both A-theorists, who think that tensed language demonstrates the existence of tensed facts, and B-theorists, who think that they can demonstrate the existence of tenseless facts by translating tensed sentences, commit the representational fallacy. In each of their respective arguments, they move from facts about language to facts about reality. Next, I will argue that both A-theorists and B-theorists end up committing this fallacy due to a flawed assumption about the relationship between language and reality. I will argue that this assumption is false, and I will write about how the possibility of moving past the debate from language depends on rejecting this flawed assumption. Lastly, I will present two new responses the B-theorist can give to the original A-theory argument from tense, thus proposing a new way of doing Metaphysics. ${ }^{4}$

\section{WHAT IS THE REPRESENTATIONAL FALLACY?}

Before I demonstrate the representational fallacy in the ontology of time, I will first introduce it and talk about why it is fallacious to move from premises about language to conclusions about reality. "The term 'representational fallacy' refers to a general philosophical tendency to place too much emphasis on the significance of language when doing ontology" (Dyke 2007:14). This fallacy does not refer to one invalid argument, or form of argument; instead, it indicates a fallacious strategy of reading Metaphysics off of language (Dyke 2007:7). Reading Metaphysics off of language makes language, rather than reality, the starting point in our investigations.

What does it mean to read Metaphysics off of language? Take the sentence "Asking two girls to the prom left Bill in a quandary." Let us suppose it is a true sentence. If a philosopher argues that reality includes the existence of entities called quandaries, based on the fact that a quandary occurs in this true sentence, then the philosopher is reading ontological facts off of language. In this case, he is reading a true sentence and deciding that, based on the fact that this sentence is true, there must exist entities called quandaries. But this is absurd. There is nothing about this sentence that tells us the sentence is made true because there are entities called quandaries that exist (or that we must posit entities such as quandaries). The truth of this sentence does not entail the existence of entities called quandaries. Thus, the philosopher who makes this move is reasoning fallaciously. In this case, the philosopher is committing the representational fallacy.

Dyke believes that philosophers who commit this fallacy are either implicitly or explicitly assuming that there is only one way in which our world can be based on our true sentences about it, and that examining these sentences will reveal the nature of reality to us. (Dyke 2007: 63) However, this is a mistake. A single language is compatible with many opposing ontologies, so it cannot be the case that a close

4 This paper and its arguments are largely inspired by Heather Dyke. 
examination of that language would reveal to us the true nature of reality. Let us consider, for example, a simple language that consists of just proper names and predicates, and suppose that some of the sentences in this language are true. One interpretation of such a language might be immanent realism, where proper names refer only to particulars and predicates refer only to the universals of immanent realism. ${ }^{5}$ Another interpretation of such a language might be Platonism, where proper names refer only to objects in the world of appearances and predicates refer only to the Forms. ${ }^{6}$ Additionally, trope theory, resemblance, nominalism, class nominalism, and any other variant of nominalism all can be plausible modes of interpreting such a language. (Dyke 2007: 64) Moreover, nothing about this language decides which of these interpretations is the right interpretation. All we can say, if backed with metaphysical and/or scientific arguments, is that one of these interpretations is right, and that we can use our simple language to help describe our true ontology.

To illustrate this point further, I will consider an example adapted from John Heil. If we take a billiard ball, there are many true ways of describing it. You may say that "the billiard ball is spherical," or that "the billiard ball is red." Many predicates hold true of it. But "to imagine that to every significant predicate there corresponds a property, [for instance,] is to let language call the shots ontologically." For instance, to imagine that there must exist a property that corresponds to the significant predicate "is spherical," because it occurs in a true sentence, is to let language dictate ontology. It could be the case that there is a property corresponding to the predicate "is spherical," but language cannot tell us this. Language cannot tell us what makes the statement the billiard ball is spherical" true. And inferring that there must be a property "is spherical" or "is red" simply because we know that these properties are true of the billiard ball (that it is spherical and red) is committing the representational fallacy. The truth of the sentence does not entail the existence of these properties - this is reading ontology off of language. Instead, what makes these truths true could be because they "participate in the form of redness, belongs to a resemblance class of red things, has a red trope." But "knowing that [the sentence] is true, even knowing what its truth-condition is, does not tell us what it is about the world that makes it true." (Dyke 2007: 65) For this reason, Dyke suggests that instead of looking at sentences we take to be true and deducing metaphysical conclusions from them, we should to the world to explain how our true sentences become true.

I have just introduced the representational fallacy, explained how it is committed, and suggested a new form of metaphysical enquiry. I will now address immediate, and potential objections to this new methodology.

5 Dyke suggests "universals are tied to particulars by the relation of inheritance, whereby a universal inheres in a particular" in this case. (Dyke 2007: 64)

6 Dyke suggests "The relation that ties objects to the Forms is that of participation" for this example. (Dyke 2007: 64)

7 John Heil. Philosophy of Mind: A Contemporary Introduction, 204. New York: Routledge. 2013. 


\section{OBJECTIONS TO THE NEW METHODOLOGY}

A philosopher might object to the new methodology by claiming that we cannot say that our true sentences, such as "the billiard ball is spherical," tell us something about reality if we claim that facts about language can tell us nothing about reality. After all, "the billiard ball is spherical" is a linguistic claim (insofar as it is a linguistic entity; a sentence), and it is one we take to be true. The philosopher might add, "your recommendation is that we attend to reality itself, rather than to language, when doing Metaphysics. But how do we do this? We come up with theories that we express in sets of sentences that we take to be true." Based on this, the philosopher might conclude, with respect to these sentences, that we are either being inconsistent (and must deny these sentences can tell us anything about reality), or that we are committing the representational fallacy ourselves when attending to these sentences. ${ }^{8}$

This objection misunderstands the nature of the representational fallacy. Simply using language to say what the world is like is not committing the fallacy. We must, of course, use language to articulate our theories. That is not a problem. The problem appears when we use language to defend our ontological claims (i.e., when we claim that there must exist a property corresponding to "is spherical" because it is a significant predicate and because "the billiard ball is spherical" is a true sentence). As long as the reasons we use to support our claims are metaphysical and/or scientific, for instance, and do not have to do with language, the fallacy has not been committed. Thus, I do not commit the fallacy by merely stating that "the billiard ball is spherical" is true, as I am not using the truth of the sentence to argue for the existence of a property that corresponds with its significant predicate. "The representational fallacy occurs when claims about descriptions of reality are taken to generate a Metaphysics, not when claims about reality itself (which, of course, are couched in language) are taken to do so." (Dyke 2007: 5)

The philosopher may concede that it is fallacious to draw ontological conclusions from descriptions about reality ${ }^{9}$, but he may insist that it cannot be fallacious to draw ontological facts from true descriptions of reality. The philosopher might add that the fact that ontological conclusions do follow from true descriptions is a consequence of the truth schema. For example, "the billiard ball is spherical" is true if and only if the billiard ball is spherical. ${ }^{10}$

This objection cannot mean that the truth schema itself entails the billiard ball is

8 This objection and its response can be found in Dyke (2007). In Metaphysics and the Representational Fallacy, 4.

9 Descriptions about reality are descriptions created using language, sentences or linguistic entities to illustrate reality (they may try to show or capture how reality is).

10 This objection and its response can be found in Dyke (2007). In Metaphysics and the Representational Fallacy, 5. 
spherical. Otherwise, "Phoenixes exist" is true if and only if phoenixes exist would entail the existence of phoenixes. The objection must instead mean that (1) the truth schema, (2) together with the claim that the sentence in question is true, (3) entails the ontological conclusion in question. ${ }^{11}$

But then, what ontological conclusions are we to derive from the following instances of the truth schema, together with the claim that the sentence on the left-hand side is true? 'Eating people is wrong' is true if and only if eating people is wrong; 'there are prime numbers greater than a million' is true if and only if there are prime numbers greater than a million, and even 'The teacher's resignation left the students in a lurch' is true if and only if the teacher's resignation left the students in a lurch. Are we to take the truth of these sentences, together with these instances of the truth schema, to entail to existence of, respectively, moral properties, numbers and lurches? Surely not (Musgrave 1993: 266-7). ${ }^{12}$

Additionally, it is plausible that someone admit to the truth of these sentences without also admitting to the existence of moral properties, numbers and lurches, so it cannot be the case that semantics alone gives us Metaphysics. Again, knowing that a sentence is true does not tell you what makes the sentence true; what makes a sentence true we may call its truth-maker. ${ }^{13}$

When I talk about the argument from tense in philosophy of time, I will argue that it is possible for two or more non-synonymous sentences to be made true by the same truth-maker. Sentences such as "it is raining now" and "it is raining at 5:44pm," supposing now is $5: 44 \mathrm{pm}$, are both made true in virtue of the same truth-maker, even though they are non-synonymous. ${ }^{14}$ And if it is possible for two or more nonsynonymous sentences to have the same truth-maker (i.e., the same thing that makes them true), then it does not suffice to focus on a true sentence in order to find what makes it true. In order to find the thing that makes both non-synonymous sentences true, we must appeal to metaphysical and/or scientific considerations, not linguistic ones. The truth-maker that makes both "It is raining now" and "It is raining at $5: 44 \mathrm{pm}$ " true is a fact about the world, not a fact about either of the two sentences. One implication of admitting that it is possible for two or more non-synonymous

11 e.g. (1) "Phoenixes exist" is true if and only if phoenixes exist, (2) together with the sentence "Phoenixes exist" being true, (3) entails the ontological existence of phoenixes. (This example is not meant to suggest phoenixes exist, it is only meant to clarify the objection.)

12 Dyke (2007). In Metaphysics and the Representational Fallacy, 5.

13 Truth-makers are supposed to be the facts in the world that make certain sentences true. Truth-maker and fact are used interchangeably in this paper. I will not be providing an account of truth-makers in this paper, as it is a separate dispute. Mentioning truth-makers is meant to suggest an alternative approach to certain metaphysical questions that have been using the fallacious strategy of reading Metaphysics off of language as arguments or in response to arguments. (Dyke 2007: 81)

14 And I as explained in an introductory footnote above, "It is raining now" is a sentence with tense, or a tensed sentence, since it refers to the moment of time that it is uttered (the present). "It is raining at 5:44pm" is not a tensed sentence, since it does not take the moment of time that it is uttered (the present) into consideration. When I talk about different ways of thinking about time in section 5, I will argue that these two sentences are non-synonymous sentences. 
sentences to have the same truth-maker is that it is not the case that there is exactly one, but, rather, many ways to truly describe the world. ${ }^{15}$ Hence, "it is raining now" and "it is raining at 5:44pm" are both true ways to describe the world.

I will now talk about the argument from tense in the ontology of time and show how the representational fallacy has been committed in this metaphysical dispute.

\section{A-THEORY VERSUS B-THEORY}

For the remainder of my paper, I would like to draw upon a case-study that shows the representational fallacy in practice. It is the argument from tense in the A-theory versus B-theory debate in the ontology of time. First, I will define the A-series and B-series, and give key terms associated with them. Then, I will write about the argument from tense.

John McTaggart distinguished two ways of thinking about time. ${ }^{16}$ One way is the A-series, which is the series that takes our common-sense distinction between past, present and future to be true, and says that there is a real ontological distinction between them. The other way is the $B$-series, which is the series that accepts that all time is real, and posits that there is no ontological distinction between the past, present and future. B-theorists believe the fact that we draw a distinction between past, present and future in ordinary life is reflective of our perspective on temporal reality. ${ }^{17}$ Time is seen as dynamic for the A-series, since what was future is now present, what was present is now past, and not for the B-series, since time does not flow in the way just described. Along with their respective ontological views of time, key terms are associated with each of them. The A-series is typically associated with the terms pastness, presentness, and futureness. Phrases such as, "today", "yesterday", "five weeks ago" and "three hundred years from now" are part of the A-series conception of time and are called tensed phrases. The B-series is associated with the terms simultaneous with, earlier than and later than. That is, event 1 is simultaneous with event 2 in time, for instance, or event 1 is earlier than event 2. Phrases such as, "two months after September 11th, 2001" or "on April 5th, 1688" are consistent with the B-theory of time, and are called tenseless phrases. ${ }^{18}$

In the debate from tense, the A-theorist takes phrases with tense such as "Tomorrow I will get my hair cut" or "Today was a good day" to represent facts about reality. The A-theorist believes that the fact that we say things like today and tomorrow, which correspond with our true sentences, means that there must exist some ontological

15 This claim does not need to commit a philosopher to antirealism, Dyke (2007). In Metaphysics and the Representational Fallacy, 89-90. For the purposes of my paper, it is not important that I show why.

16 McTaggart. The Nature of Existence, Vol. II. Cambridge: Cambridge University Press. 1927.

17 B-theorists are also generally eternalists, or accept the block view of time. Imagine time as a big block, and if you move along the block you will see different moments of time. In this way, time is viewed similarly to space.

18 Distinction between A-series and B-series is also found in Dyke (2007). In Metaphysics and the Representational Fallacy, 37-8. 
properties such as today and tomorrow. Hence, the philosopher who accepts A-theory would argue that since the B-series cannot account for these phrases in their ontology of time, it must be false. The old B-theorist response to this argument would be to say that it is incorrect, because they could provide the A-theorist with synonymous paraphrases that capture those A-series phrases. Without moving any further, it is obvious this "debate takes as its starting point our ordinary temporal language and asks what this tells us about the nature of time itself." (Dyke 2007: 9) The debate moves from facts about language to facts about reality. In the next part of my essay, I will argue that both A-theorists, who believe tensed language demonstrates the existence of tensed facts, and B-theorists, who think they can demonstrate the existence of tenseless facts by translating tensed sentences, commit the representational fallacy. They both assume that we can read ontological conclusions off of our temporal language.

\section{THE REPRESENTATIONAL FALLACY IN THE ONTOLOGY OF TIME}

Much of early A-theory work argued that tense could not be eliminated from natural language without loss of meaning. From this, the A-theorists concluded that temporal reality itself must be tensed. This argument moves from premises about temporal language to conclusions about reality. They argued that tense was not eliminable because no tenseless sentence conveys as much information as a tensed sentence. In his "Tensed Statements," Richard Gale gives an example to highlight this. Suppose Joe's job is to inform his military company when the enemy are within 100 yards of their post. If Joe yells (the tensed sentence) "The enemy are now within 100 yards," his company will be warned of the enemy's position and can take appropriate action. If Joe, instead, yells (the tenseless sentence) "The enemy are within 100 yards at $2: 15 \mathrm{pm}$," his company will not be warned unless they know that now is $2: 15 \mathrm{pm} .{ }^{19}$ For this reason, A-theorists have concluded that "since tensed expressions convey more information than tenseless sentences, there must exist something in reality that corresponds to this additional information conveyed." (Dyke 2007: 40) There must exist properties in reality that correspond to the tense in our sentences, they say. This example successfully shows that we cannot translate tensed sentences into tenseless sentences without loss of meaning. However, the example does not warrant drawing the conclusion that reality must thereby be tensed, as that commits the representational fallacy. After all, someone could accept that tensed sentences cannot be translated without loss of meaning, while also believing that reality is actually tenseless. William Lane Craig (2000) is an A-theorist who has recently made this fallacious move. His argument is as follows:

P1: Tensed sentences ostensibly ascribe ontological tenses.

19 Gale: 1962; Dyke 2007: 40 
P2: Unless tensed sentences are shown to be reducible without loss of meaning to tenseless sentences or ontological tense is shown to be superfluous to human thought and action, the ostensible ascription of ontological tenses by tensed sentences ought to be accepted as veridical.

P3: Tensed sentences have not been shown to be reducible without loss of meaning to tenseless sentences.

P4: Ontological tense has not been shown to be superfluous to human thought and action.

C: Therefore, the ostensible ascription of ontological tenses by tensed sentences ought to be accepted as veridical.

(Craig 2000: 22; numbering of premises changed) ${ }^{20}$

He moves from the claim that tensed sentences are not reducible, without loss of meaning, to tenseless sentences to the conclusion that we ought to accept that the tense given by our tensed sentences is true of reality. Craig believes that in order to refute his argument, the B-theorist must either refute $\mathrm{P} 3$ and show that tensed sentences can be translated into tenseless sentences, or refute $\mathrm{P} 4$, and show that tensed facts are not required for human thought or action. This, nonetheless, is a false dilemma. The B-theorist could maintain both $\mathrm{P} 3$ and $\mathrm{P} 4$ and, instead, reject P2. He thinks P2 "has offered the B-theorist her only escape route from the conclusion of his argument." (Dyke 2007: 43) Yet, this is not true. The B-theorist could agree with both P3 and P4 - that tense cannot be eliminated and is needed for human thought and action - and believe that these true tensed sentences are made true by tenseless facts. I have just shown how the A-theorist moves from premises about temporal language to facts about reality in the debate from tense and suggested an alternative response for the B-theorist. I will now discuss an old B-theorist response to this debate.

B-theorists believe that there are no tensed facts and no tensed properties- the fact that we say things like today and tomorrow, for instance, is reflective of how we perceive time, not of time itself. The old B-theorists tried to prove this by rejecting $\mathrm{P} 3$, or by showing that tensed expressions can be eliminated from natural language. (Russell 1915; Goodman 1951: 287-301; Quine 1960: 36; Smart 1963: 132-42). ${ }^{21}$ B-theorists tried to appeal to parsimony or Ockham's razor to support their claim that tenseless sentences displayed the true nature of reality, since tenseless sentences on their own imply the existence of fewer entities than tensed sentences (and are thus preferred) (Dyke 2007: 43). B-theorists concluded from this that tensed sentences are eliminable, since there is no feature of reality they actually describe, and tried to translate tensed sentences into tenseless sentences. These B-theorists believed

20 (Dyke 2007: 42)

21 (Dyke 2007: 43) 
that their translation project was successful, having demonstrated the existence of only tenseless facts, and that there was no ontological distinction between past, present and future. Their translation project was unsuccessful, however. As we saw in Gale's example above, it is not possible to translate tensed sentences into tenseless sentences without some loss in meaning (see Joe's informing the military company example). Tense in language is a context-dependent phenomenon, since whether or not a sentence is true depends on the time it was uttered. ${ }^{22}$ Not only was his translation project unsuccessful, but the B-theorist who argues that translating tensed sentences into tenseless sentences shows there are only tenseless facts, commits the representational fallacy. Their argument is no different from the A-theorist's, as both move from facts about language to facts about reality.

Why do both the A-theorist and B-theorist make this move? Dyke suggests that there must be a hidden assumption that they both accept, which is informing the move from making purely linguistic claims to concluding ontological ones. It is my, and Heather Dyke's, view that these philosophers are assenting to the assumption that there must be "a privileged, true description of reality, which can inform us about the ontological nature of reality." (Dyke 2007: 44) This makes up part of a thesis called the Strong Linguistic Thesis (SLT). In the next section of my paper, I will show why the A-theorist and the B-theorist must assume SLT for their debate to make sense, and then, I will subsequently refute SLT.

\section{STRONG LINGUISTIC THESIS (SLT)}

The Strong Linguistic Thesis (SLT) says that "there is one privileged, true description of reality, the sentences of which (a) stand in a one-to-one correspondence with facts in the world, and (b) are structurally isomorphic to the facts with which they correspond." (Dyke 2007: 46) There are a couple of ways of understanding "one true description of reality." I believe the A-theorists and B-theorists are understanding it to mean that "there is one true description of reality which contains a subset of all the truths that there are. This subset of truths is ontologically perspicuous, in that each truth in it reveals the nature of the fact that it describes, and that makes it true." (Dyke 2007: 45-46) In other words, they must accept (1) with each true proposition there corresponds a single truth, and (2) each true proposition tells of the nature of its truth. For this reason, there can only be one fact per linguistic utterance, one truth-maker per sentence. If there were more than one, a choice would have to be made between them. SLT thus involves a commitment to the claim that there is a one-to-one correspondence between truths in the one true description of reality and truths in the facts about the world. (Dyke 2007: 46)

22 "This conclusion was originally arrived at by philosophers working in the philosophy of language, on the linguistic phenomena of indexicals and demonstratives. These philosophers established that no sentence containing a context-dependent expression, like an indexical or a demonstrative, could be translated by any sentence that was wholly context dependent (Castańeda 1967; Perry 1979).” (Dyke 2007, 44) 
I will now argue that philosophers must either knowingly or unknowingly accept SLT in order for certain metaphysical debates, like the debate from tense in the ontology of time, to make sense. In order for A-theorists to reach the conclusion that reality must be tensed because language is tensed, they must think (1) there is a fact corresponding to every truth in that description, and, (2) that the truths are structurally isomorphic to facts. (Dyke 2007: 46) Without (1) A-theorists could not infer there are any facts in reality that correspond to their true tensed phrases, and without (2) A-theorists could not infer that these corresponding facts must be tensed. ${ }^{23}$ The same applies for old B-theorists of time. Without (1) B-theorists could not infer there are any facts in reality that correspond to their true tenseless phrases, and without (2) B-theorists could not infer that those corresponding facts must be tenseless. ${ }^{24}$

Now, it may be that if presented with SLT, most philosophers would reject it. Regardless of whether or not philosophers think it is false on its own merits, it needs to be assumed in order for certain arguments, such as the argument from tense, to make sense. "Once we make it explicit, and then reject it we can see that those disputes are by and large, fruitless.” (Dyke 2007: 47) I will now argue against SLT.

The component of SLT that I am arguing against is that there is one privileged, true description of reality, "where that description is taken to be a subset of all the truths that there are, and where the sense in which it is 'privileged' is that it contains ineliminable kinds of term." (Dyke 2007: 72) SLT is false because the fact that true sentences contain property terms does not entail the existence of these properties. (Dyke 2007: 72) As I argued in section 2, nothing about our language tells us what makes our sentences true, and the truth of certain sentences does not entail the existence of certain properties. Since I am denying that there is one privileged, true description of reality, in this sense, I am also denying that there is a one-to-one correspondence between truths and facts. The ratio of truths to facts is many-to-one, as I showed in section 3. There are many ways to truly state a fact, since two or more non-synonymous sentences can be made true by the same truth-maker. Both "it is raining now" and "it is raining at 5:44pm" are made true by the same truth-maker, the same fact in the world, and, thus, they are both accurate ways of describing that fact. The fact that there is a many-to-one ratio allows for there to be better or worse descriptions of any fact. For instance, "it is raining at 5:44pm" would be a better way to most accurately describe its truth-maker if you are a B-theorist, and "it is raining now" would be a worse way. But what it does not allow is the inference that since a sentence cannot be paraphrased, there must exist a fact that can only be described by that truth. Thus, I reject that there need be any isomorphism between truths

23 "Without (1), the A-theorist would not be able to infer that there are any ontological counterparts to her tensed truths. Without (2) she would not be able to infer that those ontological counterparts are tensed." (Dyke 2007: 46)

24 "Without (1), she would not be able to infer that there are any ontological counterparts to her tenseless truths. Without (2) she would not be able to infer that those ontological counterparts are tenseless." (Dyke 2007: 46) 
and the facts that they describe. There may be isomorphism between truths and the facts that they describe, but we cannot rely on this possibility in all cases. Hence, we cannot draw conclusions about the ontological nature and structure of our reality from claims about the nature and structure of reality of our true sentences. (Dyke 2007: 72-3)

I have just shown how the A-theorist and old B-theorist must accept SLT in order for the argument from tense to make sense, delineated SLT, and argued against it. I will now give a couple of new B-theorist responses to the argument from tenseone is the truth-condition variant of the new B-theory, and the other is the truthmaker variant of the new B-theory. Then, I will argue against the truth-condition variant, since it also places too much emphasis on language, and support the truthmaker variant of the B-theory of time on the grounds that it is in line with our new metaphysical enquiry.

\section{TRUTH-CONDITION VS. TRUTH-MAKER VARIANT}

New B-theorist responses emerged because of the failure of the old translation project. These B-theorists realized that they needed new ways to respond to the A-theorist's argument from tense. The first way in which the new B-theorist responded was by the truth-condition variant of the B-theory. The second was by the truth-maker variant of the B-theory. I will first show how the truth-condition variant is also prone to committing the representational fallacy, and then I will advocate for the truth-maker variant of the B-theory of time as an alternative approach.

Proponents of the new B-theory of time agree that tense cannot be eliminated from language, but disagree whether this means that reality is itself tensed. "Proponents of the truth-condition variant argue that, while it is not possible to translate any tensed sentence into a tenseless sentence, it is possible to state the truth-condition of any tensed sentence in entirely tenseless terms." (Dyke 2007: 47-48) In other words, they believe that it is possible to state the conditions in which the world must be for the sentence to be true. For instance, if we take the utterance "the enemy is now approaching," then the truth-condition B-theorist would say "the enemy is now approaching" is true, if and only if the enemy's approach is tenselessly simultaneous with the sentence "the enemy is now approaching." That is to say, the condition in the world it takes for "the enemy is now approaching" to be true, is that the enemy approaches at $2: 15 \mathrm{pm}$, when "now" is uttered it is $2: 15 \mathrm{pm}$. There are a couple of ways to construct this approach. One is to say that they argue that since tensed sentences can be given tenseless truth-conditionals, reality is tenseless. Another way is to say that the new B-theorist has separate arguments for the B-theory account of time, and that he offers the tenseless conditional alternative, not as an argument for B-theory, but as a way to show how the semantics of tensed sentences are compatible 
with B-theory. (Dyke 2007: 48) The latter approach is fine; the former is fallacious.

Some philosophers believe that if we know the conditions it takes for a sentence to be true, then we know what the world must be like in order to make that sentence true: "so, if a sentence is true, we know what the world, as described by that sentence, is like." (Dyke 2007: 73) However, it is a mistake to think that knowing the conditions it takes for a sentence to be true can generate ontology, since that is just another way of trying to read ontological facts off of language. Arguing from the claim that tensed sentences can be given tenseless truth-conditionals, to the claim that reality is tenseless, commits the representational fallacy. "This suggests that we are able to determine whether a sentence is true or false just by examining its truth-condition, but this is not true. Examining its truth-condition will tell us what must be the case for the sentence to be true." (Dyke 2007: 50) Stating the truth-condition of a sentence is specifying what the world must be like in order for that sentence to be true-it does not tell us whether the truth-condition is actually upheld by reality. In order to know this, we must appeal to metaphysical and/or scientific considerations. If truthcondition B-theorists argue from the claim that we give our tensed sentences tenseless truth-conditionals, to the conclusion that reality is thereby tenseless, then they seem to use the same fallacious strategy that the A-theorist and the old B-theorist of time used. This strategy accepts SLT, which I argued is false in section 6. I have just argued against using tenseless truth-conditionals as an argument for the B-theory of time. I will now introduce the truth-maker variant of the B-theory of time.

The significance of the truth-condition project was to state what the world must be like in order to make our sentences true. However, "by focusing on this notion of how the world makes a true sentence true instead of on how to state the truthcondition of a tensed sentence, one arrives at the truth-maker variant of the new B-theory." (Dyke 2007: 54) What distinguishes the truth-condition variant from the truth-maker variant of the B-theory is that the truth-maker variant is a purely ontological thesis. The truth-maker variant of the B-theory makes the world, instead of language, our starting point. It takes ontological facts about time, and uses them to explain the semantics of our temporal language. The truth-maker variant of the B-theory also holds that tense cannot be eliminated from language, but denies this means temporal reality is tensed. Thus, it rejects SLT - that sentences of that description stand in a one-to-one correspondence with the facts in the world, or that those sentences need be structurally isomorphic to the facts that make them true. (Dyke 2007: 55) Though they believe that tensed sentences cannot be eliminated or reduced to tenseless sentences, this belief does not entail that there exist some extralinguistic ${ }^{25}$ tensed fact that corresponds to the tensed sentence. What makes these tensed sentences true are truth-makers — scientific and/or metaphysical reasons, and not linguistic ones.

25 Extra-linguistic simply means beyond linguistics, or something that is not language. 
What should be taken away from all of this? Philosophers should stop looking at our language in order to discover facts about reality. As I have shown in my paper, our language cannot reveal ontological facts to us, for there is nothing about a sentence that tells us what makes it true (see section 2). There are also additional reasons to believe that sentences do not reveal their truth-makers to us. Competent language speakers may understand the sentence "the ball is red," and see that it is a true sentence under the right conditions, without understanding what makes this sentence true. What makes the sentence true could be that the ball exemplifies universal redness, or has a red trope. But nothing about this sentence could tell a competent languagespeaker that. ${ }^{26}$ In order to know this fact-how the sentence comes to be true-we need to attend to metaphysical and/or scientific considerations. For this reason, we should attend to reality itself while doing Metaphysics, the parts of reality that are the truthmakers of our sentences, and, from there, see how our sentences get to be true.

\section{CONCLUSION}

In this paper, I criticized a fallacious methodology by introducing the representational fallacy. I explained that this fallacy is committed when philosophers place too much emphasis on language while doing Metaphysics. I gave immediate objections to the new methodology, and then displayed, and betrayed, the fallacy in the argument from tense in the philosophy of time. I argued that philosophers must either implicitly or explicitly accept the Strong Linguistic Thesis (SLT) in order to warrant the move from language to reality and for certain metaphysical disputes to make sense. My paper argued that A-theorists and B-theorists assent to SLT in their argument from tense, and then proceeded to refute SLT. I concluded by providing some new B-theorist responses to the argument and suggested a new way of doing Metaphysics. "A fallacy is just an invalid argument and recognizing that an argument is invalid does not permit the inference that its conclusion is false." (Dyke 2007: 60) This paper is not meant to disprove the A-theory of time and does not entitle us to conclude the A-theory of time is false. It is meant to show that it is erroneous to argue from language to reality. Hence, A-theorists are not entitled to use this argument when arguing for their position. If the A-theory is correct, then they must use other arguments to justify their ontological stance on time. This paper also did not argue that the B-theory changed their stance on time. Both the old and new B-theorists maintain the same metaphysical views, this has not changed. What has changed is their methodology. The old B-theorists thought when presented with the argument from tense their job was to offer translations to show how facts about the world were actually tenseless. But as I have argued for in my paper, this move commits the representational fallacy. The new B-theorists agreed with the A-theorists that tense was not eliminable from natural language; however, they rejected the translation project and maintained reality was still tenseless. Two responses emerged from this, the truth-condition and

26 Example inspired by Dyke (2007). In Metaphysics and the Representational Fallacy, 73-4. 
truth-maker variant of the B-theory of time. Ultimately, the truth-condition variant, if used as an argument for the B-theory of time, also committed the representational fallacy. For this reason, I advocated for the truth-maker variant of the B-theory of time in order to avoid reasoning fallaciously. The truth-maker variant of the B-theory relies on metaphysical and/or scientific considerations in order to reach metaphysical conclusions. It starts from reality and uses it to explain language. At the end of the day, I believe, we should reject the view that there is a certain privileged language or description of reality that we can read off of, which will tell us the way the world is.

\section{BIBLIOGRAPHY}

Dyke, Heather. Metaphysics and the Representational Fallacy. London: Routledge, 2007.

Heil, John. Philosophy of Mind: A Contemporary Introduction. New York: Routledge, 2013.

Musgrave, Alan. Common Sense, Science and Scepticism: A Historical Introduction to the Theory of Knowledge. Cambridge: Cambridge University Press. 1993.

McTaggart, John M.E. The Nature of Existence, Vol. II. Cambridge: Cambridge University Press, 1927.

Gale, Richard M. “Tensed Statements,” Philosophical Quarterly. 1962.

Craig, William L. The Tensed Theory of Time: A Critical Examination. Dordrecht: Kluwer Academic Publishers, 2000.

Castañeda, H.-N. "Indicators and Quasi-Indicators," American Philosophical Quarterly. 1967.

Perry, John. "The Problem of the Essential Indexical," Nồs. 1979.

Russell, Bertrand. “On the Experience of Time." The Monist. 1915.

Goodman, Nelson. The Structure of Appearance. Cambridge, Mass.: Harvard University Press. 1951.

Quine, Willard V.O. Word and Object. Cambridge, Mass.: MIT Press. 1960.

Smart, John J.C. Philosophy and Scientific Realism. London: Routledge \& Kegan Paul. 1963. 